\title{
CORRECTION
}

\section{Correction to: A review of the water-energy-food nexus measurement and management approach}

\author{
F. M. Tashtoush ${ }^{1}$-W. K. Al-Zubari ${ }^{1}$ - A. Shah ${ }^{2}$
}

Published online: 14 March 2020

(c) Islamic Azad University (IAU) 2020

\section{Correction to: \\ International Journal of Energy and Water Resources \\ (2019) 3:361-374 \\ https://doi.org/10.1007/s42108-019-00042-8}

In the original publication of the paper the affiliations of the authors were not correct. You can find the corrected affiliations below.

The original article can be found online at https://doi.org/10.1007/ s42108-019-00042-8.

A. Shah

afzals_qau@yahoo.com

1 Department of Natural Resources and Environment, College of Graduate Studies, Arabian Gulf University, P.O.

Box 26671, Manama, Kingdom of Bahrain

2 Department of Chemistry, Quaid-i-Azam University, Islamabad 45320, Pakistan 